\title{
Participatory Communication and Information Management for Community Development: Thai Rural Community Perspectives ${ }^{*}$
}

\author{
Chintawee Kasemsuk \\ Sripatum University, Bangkok, Thailand \\ Vatanavongs Ratanavaraha \\ Suranaree University of Technology, Nakhonratchasima, Thailand
}

\begin{abstract}
The application of participatory communication approach and information management relating to community development in developing country such as Thailand is required. The objectives of this research are: (1) to provide and strengthen participatory communication and information management in order to support community development at the level of rural community; and (2) to investigate the participatory communication characteristics those provide community leaders for rural community development. Population and study area of this research included community leaders and members who live within the selected rural community. The quantitative data collection is applied through surveying community leaders and members identified as the key informants as well as referable and reliable data source. The purposive random sampling is used for selecting rural community areas by focusing on the case of strengthening community development that is "Banjumrung Community" (Muban) located at Noen Kho sub-district (Tambon), Klaeng district (Amphoe), Rayong Province, eastern Thailand, where the community was awarded in the best model of sufficient economy village according to the philosophy of “sufficiency economy” which has been widely adopted in Thailand. This study found that rural community leaders need to have a comprehensive knowledge of external sources as they need to create the input process of communication by receiving useful information from the outside and then transmit them to the community. Consequently, community leaders have to be alert to all situations and try to manage information to facilitate communication with community members. This can help everyone become aware of and understand the same information correctly.

Keywords: participatory communication, information management, community development, Thai rural community
\end{abstract}

\section{Introduction}

Developing community has attracted the attention of many researchers in recent years. Community may be

\footnotetext{
*Acknowledgment: This research was funded by Thailand Research Fund, Office of the Higher Education Commission and Sripatum University. We are very grateful to Prof. Dr. Parichart Sthapitanonda for her useful advice, and also to the participants of Banjumrung Community for their continual support to complete the study.

Chintawee Kasemsuk, Ph.D., Assistant Professor of Faculty of Communication Arts, Sripatum University.

Vatanavongs Ratanavaraha, Ph.D., Associate Professor of Institute of Engineering, Suranaree University of Technology.

Correspondence concerning this article should be addressed to Dr. Chintawee Kasemsuk, 61 Phaholyothin RD., Bangkok 10900, Thailand. E-mail: chintawee.ka@spu.ac.th.
} 
viewed as systems composed of individual members and sectors that have a variety of distinct characteristics and interrelationships (Thompson \& Kinne, 1990). Importantly, community development requires suitable medium as a tool to bring all information from government or private agencies to people who have the main target of such development. Therefore, it is important to stimulate and motivate people or community members to perceive community leaders who are regarded as the closest media to the community members. Community will develop if leader and members in the community communicate with each other, exchange opinions and conduct activities to reach their goals. Therefore, communication within the community is a significant mechanism to drive community power to become a "strengthening community".

Personal media may be a well-known or acknowledged person within the target audience including opinion leaders and community leaders who are familiar and reliable media for the community. Personal media such as community leaders, therefore, are considered as the persons who bring useful information and create participatory communication of people in the community. The community leaders are regarded as a significant mechanism to build relationships between people in the community. Besides, they may initiate innovative ideas to turn into action and development for positive change in the community which is participating in development to generate benefits for the people in the community.

Most researchers tend to study about community leader and community development in the context of rural community. Ozor and Nwankwo (2008) studied the role of local leaders in community development programs in Ideato and derived implications for local leadership as an institution for extension policy. Results showed that the most important roles played by local leaders in community development were decision-making, liaison between governmental and non-governmental agencies and the community for financial and technical assistance, monitoring and evaluation of projects, and fund raising for projects. Further results showed that the most important source of information for community development efforts were through the local leaders themselves.

Kuponiyi (2008) investigated the participation of local leaders in decision-making in Ajaawa community of Oyo State, Nigeria. Results revealed that major areas of decision-making where leaders regularly participate are religion, chieftaincy, community safety, and community development.

Ricketts and Place (2009) compared two particularly successful rural communities, focusing on the importance of leadership within the community. Four significant factors were determined to set these successful communities apart from those less viable-effective communication, development of social capital, community engagement, and collaboration across and within communities.

Similarly, the majority of research on personal media in Thailand tends to favor the context of the rural community. This is because the majority of Thai people live in rural areas. Therefore, this research focuses on investigating significant characteristics of rural community leaders to the extent that they constitute participatory communication and information management for community development.

\section{Review of Literature}

\section{Development Communication}

Development means problem-solving to improve the living conditions of people in a society (Melkote, 2001) or bringing new ideas to the social system to enhance or change living conditions for the better (Rogers, 1995). It can be said that the development is a concept which can lead to changes for the better. It is also about planned change through government mechanisms whereby the government defines the purposes of 
development based on the problems and needs of the people.

Development communication was regarded as an aspect of communication depending on the mass media rather than other types of media to create modernity and to be concordant with development concepts. However, it changed to emphasize participatory communication based on the community which mainly aims to respond to community needs. It can be said that communication and participation within the community will lead to community development. For this reason, "personal media" has become a more interesting means of communication because it is very helpful for development.

Considering the advantages and disadvantages of each type of media, it is essential to combine several media into a media forum including personal media, specialized media, and mass media. Personal media is persuasive while mass media can spread the news to many people quickly and widely. Furthermore, specialized media can provide content suitable for the target audience. This combination of three types of media helps enhance the efficiency of development communication. Thus, there is a reaction between communication and development, both through channels of mass media and interpersonal communication. This can lead to various changes to people and society on such as attitudes and behaviors as well as further development.

\section{Personal Media for Community Development}

Every person has a unique identity which nobody else can perfectly imitate. An important function of communication is to stimulate and motivate community members to gain correct information and this requires community leaders because they are the closest personal media for the community. Personal media such as community leaders are considered persons who are able to convey information to members. This system brings new information from outside to the community. It is an effective method of persuading people in the community to respond favorably to the purposes of such communication. It can be concluded that personal media in the community are more significant than external media in the process of decision-making to acknowledge innovation (Rogers \& Svenning, 1969).

In Thai context, community leaders should play a communication role in the community as follows (Kaewthep et al., 2008):

- be open to external communication with the community;

- be able to transform the messages in accordance with the levels of knowledge of community members;

- be able to strengthen networks within the community;

- be a catalyst for engaging individuals in decision-making and action;

- be able to create a sense of community;

- be able to develop transparency in the community;

- be able to arrange a forum to exchange information within the community;

- be able to enhance people's ability to become involved in their community and work together;

- be able to manage conflicts in the community;

- be able to listen to opinions and needs of community members;

- be a representative for community members.

These communication roles can activate participatory communication within the community in many ways. Importantly, the ability to play the communication role in various situations is different. Sometimes, they are leaders and at other times they are followers. These kinds of events demonstrate the leadership qualities of each person which may assist or obstruct community leaders depending on the situation. This is because of diverse 
dimensions of the characteristics of the personal media that is beneficial for community engagement to develop the community.

\section{Participatory Communication for Community Development}

The study covered by participatory communication has broadened considerably in recent years. Erwin (1976) illustrated that participation was a process enabling people involved in the development implementation through cooperative thinking, making decision to solve their own problems, creating innovations, knowledge and skills in a proper manner as well as monitoring the implementation performance of organization. It can be summarized the term "participation" in the meaning of providing the opportunity for individuals helping each other, especially in cooperative thinking, decision-making, implementing, and taking responsibility of any subjects that would have impacts on public in order to achieve social goals. Therefore, participation may refer to people or communities developing their capacities in managing and controlling the use of available resources and factors of production in society to get benefits of economic and social livings as well as any decisions relating to appropriate and acceptable projects.

Generally, four different ways of participation can be observed in most development projects claiming to be participatory in nature (Uphoff, 1985). They are:

- Participation in implementation: People are actively encouraged and mobilized to take part in the actualization of projects. They are given certain responsibilities and set certain tasks or required to contribute specified resources;

- Participation in evaluation: Upon completion of a project, people are invited to critique the success or failure of it;

- Participation in benefit: People take part in enjoying the fruits of a project, this maybe village meeting in the new community hall;

- Participation in decision-making: People initiate, discuss, conceptualize, and plan activities they will all do as a community.

Shirley, Sadanandan, and Joseph (1994) defined participatory communication as collaborative efforts in thinking, listening, and respecting attitudes and ideas of others. Community members need to coordinate their efforts to analyze problems of their own communities, exchange information and ideas in order to bring about appropriate changes. Yoon (2004) proposed that some of the most successful participatory communication programs were tested at the village community level. The small size of the community permitted the intensive use of interpersonal channels. People in community need to be encouraged and provided with the opportunity to participate in the planning process. Therefore, participatory communication would play an important role at this stage.

Regarding several definitions as mentioned, the successful community development would depend on the participation of people who must know "what they want" with the aim of self-development.

In the context of community development and especially in societies in the process of democratic transition, one would expect participation to lead towards a situation where all parties feel that they have the capacity to influence the development of the project (Kelly \& Vlaenderen, 1995). By means of people gathering together in the form of society or community within particular areas, this concept supports the community and society strengthening by focusing on participation that offers cooperative thinking, cooperative doing, and cooperative problem-solving. To find an effective solution for the problems, it significantly requires the 
collaboration of partnerships at all levels that need to mobilize all compositions of society, especially communities with the aim of strengthening community capacity to solve crucial problems by themselves.

\section{Information Management for Community Development}

Information management is a useful concept that facilitates participatory communication. According to Wikipedia, information management is the collection and management of information from one or more sources and the distribution of that information to one or more audiences. It can be said that information management is an application to communicate information within and outside, and process it to enable leader to make quicker and better decisions. Information management is the study of how information are created, represented, and communicated in social contexts. Ten principles to ensure that information management activities are effective and successful (Robertson, 2005):

- recognize (and manage) complexity;

- focus on adoption;

- deliver tangible and visible benefits;

- prioritize according to business needs;

- take a journey of a thousand steps;

- provide strong leadership;

- mitigate risks;

- communicate extensively;

- aim to deliver a seamless user experience;

- choose the first project very carefully.

According to Robertson (2005), effective information management focused on adoption, strong leadership, active participation, and choosing of the first project very carefully. This is to ensure that the project will reflect value of information management. However, most effective forms of communication occur when information is not only exchanged, but acted on collaboratively (Braun, Thiele, \& Fernandez, 2000). Conceptually, the characteristics of community leader such as participatory communication and information management can reflect, to some extent, the development of that community.

\section{Research Method}

\section{Research Participants}

Population and study area include community leaders and members who live within the selected rural community. The quantitative data collection is applied through surveying community leaders and members identified as the key informants as well as referable and reliable data source, such as TV program "Community Model” of Thai PBS broadcasting every Saturday from 11.05am to $12.00 \mathrm{am}$. In this step, purposive random sampling is required for selecting rural community areas by focusing on the case of strengthening community development that is "Banjumrung Community" (Muban) located at Noen Kho sub-district (Tambon), Klaeng district (Amphoe), Rayong province, eastern Thailand, where the community was awarded in the best model of sufficient economy village in 2006, according to the philosophy of "Sufficiency Economy" which has been widely adopted in Thailand. According to this reason, authors become interesting in the study of participatory communication and information management of community leaders by focusing on how they stimulate the involvement of community members in development on such community. 
Banjumrung Community (Muban) is one of Mubans which is further subdivided into 136 households. In the study, there are 136 samples of community members including two leaders who are the past and present leader.

\section{Research Design and Procedure}

This research used a quantitative method which collects data by using questionnaires to explore the opinions of community members in Banjumrung community. In addition, authors also conducted semi-structured interviews to gather additional information about the actions of management from the community leaders.

\section{Results}

Quantitative analysis and descriptive analysis were applied for data analysis including certain basic statistics such as frequency and percentage to describe important issues of the research. Moreover, the data collected from the interviews were analyzed by categorizing some significant data to complete the research.

\section{Communication Characteristics Facilitating the Participatory Communication in Community}

According to the analysis of the communication characteristics of rural community, leaders supporting the participatory communication in community (see Table 1), $91.2 \%$ of community members agreed that community leaders should listen to others' opinions and needs, whereas $91.1 \%$ agreed that the community leaders should open to external communication with the community to transmit news to members. Furthermore, they have to be able to filter the news according to the basic knowledge of the members because of varying demographic characteristics and different knowledge level in each area. Therefore, it is a duty of community leaders to try to edit external information so as to enable members to understand it clearly.

Table 1

Communication Characteristics Facilitating the Participatory Communication in Community

\begin{tabular}{lll}
\hline Characteristics facilitating the participatory communication & Mean & Percentage (\%) \\
\hline Be open to external communication with the community & 4.42 & 91.1 \\
Be able to transform messages in accordance with the levels of knowledge of community members & 4.31 & 91.1 \\
Be able to strengthen networks within the community & 4.37 & 90.8 \\
Act as catalyst for engaging individuals in decision-making & 4.23 & 87.6 \\
Be able to create a sense of community & 4.22 & 86.6 \\
Be able to develop transparency in the community & 4.40 & 89.6 \\
Be able to arrange a forum to exchange information within the community & 4.32 & 87.9 \\
Be able to encourage people to become involved in their community and work together & 4.45 & 90.6 \\
Be able to manage conflicts within the community & 4.10 & 82.5 \\
Be able to listen to opinions and needs of community members & 4.38 & 91.2 \\
Act as representative for community members & 4.40 & 89.8
\end{tabular}

Notes. $N$ = 136; Source: Retrieved from http://www.banjumrung.com/index.php/submnudatageneral.

Rural community leaders should play important role in strengthening networks within the community (90.8\%). In addition to community leaders' duty as personal media to convey external messages to the receivers in their own community, they have to act as representatives for community members (89.8\%). Most of all, they must be a catalyst for engaging individuals in decision-making and action (87.6\%).

In addition, community leaders should also be able to create a sense of community (86.6\%). Chavis and Wandersman (1990) stated that a sense of community was the glue that can hold together a community 
development effort. Nevertheless, they must be able to encourage people to become involved in their community and work together (90.6\%). They should arrange a forum for interpersonal exchange of information (87.9\%) and they should manage conflicts within the community (82.5\%).

Based on the findings, it is obviously seen that the first three characteristics present the priority to the potential capabilities of rural community leaders in screening information to community as well as transforming them appropriately based on people's background knowledge. Moreover, community leaders also stimulate participatory communication process through conveying update information from outside to inside community to provide people the opportunity to share their ideas. Hence, it might be the crucial factor influencing the participation within community.

\section{Characteristics Facilitating the Information Management Role of Rural Community Leaders}

According to the interview analysis of the characteristics supporting the information management role of rural community leaders, of course, this does not mean that every person possesses all the characteristics. As stated above, people in rural environment need leaders who can play an important role in participatory communication and also information management. This is because the daily routine of most people involves with communication all the time. As a community leader, it may need to communicate to large numbers of people. It can be said that community leaders should collect and manage of information from one or more sources and distribute that information to one or more audiences. However, both past and present leaders of Banjumrung community have to access and receive quantities of information daily, but not everyone is able to understand all information correctly and completely. They tried to use the participatory communication strategy to identify appropriate methods for approaching their community members and also have communication skills to develop a more precise understanding of the information.

In addition, both past and present leaders of Banjumrung community said that community members are actively encouraged and mobilized to take part in the actualization of community projects. They are invited to critique the success or failure of it through community meeting in every month.

Some crucial problems of the personal media are related to the lack of skills in selecting and screening useful information to transmit to other people. However, according to Robertson (2005), both past and present leaders of Banjumrung community also focused on strong leadership and active participation in order to ensure that this will reflect value of information management. Regarding the research on the participatory communication characteristics supporting the role of rural community leaders, this showed that one of three emphasized an ability to convey messages to the community members and also screen suitable information for the community members. In short, community leaders should speak to the community in a language that members understand.

\section{Discussions and Conclusions}

This research has focused on participatory communication and information management according to the first three factors encouraging the participatory communication in community development. It reveals that the first three characteristics which support a role for community leaders in participatory communication are that they: (1) should listen to opinions and requirements of community; (2) are open to external media to pass on the information to community members; and (3) are able to adapt the messages in accordance with the various levels of knowledge of community members. 
It can be concluded that rural community leaders need to have a comprehensive knowledge of external sources as they need to create the input process of communication by receiving useful information from the outside, and then transmit them to the community. It is important to say that community leaders must be prepared to work with the community to adapt any existing project ideas or activities to suit community's needs. Community leader must be stimulators to create the participatory communication process in the community by using several methods such as a meeting of community members to provide opportunities for everyone to express their own opinions. It seems like the study of Ozor and Nwankwo (2008), results showed that the most important source of information for community development efforts were through the local leaders themselves.

Consequently, community leaders have to be alert to all situations and try to manage information to facilitate communication with community members. This can help everyone become aware of and understand the same information correctly. Hence, the factors supporting these characteristics of community leaders are knowledge and understanding of communication technologies in order to connect to external sources of information easily. Therefore, government agencies or concerned departments should provide regular training to extend and improve knowledge of community leaders.

On the other hand, the characteristics impeding the use of personal media for the community development can be considered as the participatory communication characteristics of the last three factors. It can be concluded that if community leaders lack skills to manage conflict, it may confuse members and divide opinions. Community leader may need to negotiate and handle situations. Such skills cannot be found in everyone, but training is needed to reinforce the problem resolution and conflict management skills for use in the community. For this reason, the characteristics supporting good community leaders are skills to manage conflict which require collaboration with concerned agencies to hold regular training to strengthen community leaders' potential.

\section{Implications and Recommendations}

However, there is a limitation with respect to the target group including community leaders and members from only one rural community in Rayong province. According to the field survey with community leaders and members, it presents the same characteristics, in that the majority of rural community members were found in a similar low income group and living pattern as a significant factor facilitating the role of community leaders, because members have the similar history and family background. Therefore, the future research might apply this issue for the other communities that show different characteristics that would benefit to obtain information relating to the potential capabilities of community leaders in each area, as well as provide the guideline for strengthening their leadership skills in terms of communications and implementations in the community.

It is another issue for seriously study to find out that how we can develop the "people" and which methods are suitable to lead to the development of community, society, and country. Regarding previous studies by scholars, most of them illustrated that community leaders lacked communication skills, especially how to select useful information to pass on to members. It is necessary to increase the role of the community leaders to coordinate and create strong communities by improving their communication skills. Operational training to support leadership can create good leaders and make them realize their own potential as significant persons to sustain the community. It is the responsibility of communication experts to apply their knowledge of communication to support such development, such as by training to enhance public speaking skills, designing suitable content to reach the target group as far as possible to make community members change their behavior 
to adopt desirable manners.

Finally, an important suggestion for sustainable community development, particularly in Thai rural communities, is participatory communication to develop the community. This should emphasize community participation as the main paradigm of participatory communication for community development. People participate when they feel a sense of community, see their involvement and issues as relevant and worth their time (Chavis \& Wandersman, 1990). Community leaders should empower others to lead all activities in their own way. Community members will realize the importance of community development which allows them to solve problems together. This is because both community leaders and members are important participants in developing their community. Thus, it is essential to motivate community leaders into gaining proper information and understanding of participation in community development. Some activities may be initiated to attract community members into the operation of the community, for example, activities which can demonstrate the abilities of individual community members. This is regarded as personal media development from community engagement which will lead to sustainable community development for and by everyone in the community.

\section{References}

Braun, A. R., Thiele, G., \& Fernandez, M. (2000). Farmer field schools and local agricultural research committees: Complementary platforms for integrated decision making in sustainable agriculture. Agriculture Research and Extension Network, Paper No. 105, ODI, UK.

Chavis, D. M., \& Wandersman, A. (1990). Sense of community in the rural environment: A catalyst for participation and community development. American Journal of Community Psychology, 18(1), 55-81.

Erwin, W. (1976). Participation management: Concept, theory, and implementation. Atlanta, G.A.: Georgia State University.

Kaewthep et al. (2008). The principle of knowledge management: Community communication. Bangkok: The Thailand Research Fund.

Kelly, K., \& Vlaenderen, H. V. (1995). Evaluating participation processes in community development. Evaluation and Program Planning, 18(4), 371-383.

Kuponiyi, F. A. (2008). Community power structure: The role of local leaders in community development decision making in Ajaawa, Oyo State, Nigeria. Anthropologist, 10(4), 239-243.

Melkote, S. R. (2001). Communication for development in the third world (2nd ed.). New Delhi, India: Sage Publications.

Ozor, N., \& Nwankwo, N. (2008). The role of local leaders in community development programmers in idea to local government area of Imo State: Implication for extension policy. Journal of Agricultural Extension, 12(2), 63-75.

Ricketts, K. G., \& Place, N. T. (2009). Making communities more viable: Four essential factors for successful community leadership. Retrieved from http://www.joe.org/joe/2009april/iw2.php

Robertson, J. (2005). 10 Principles of effective information management. Retrieved from http://www.steptwo.com.au/papers/kmc_effectiveim/index.html

Rogers, E. M. (1995). Diffusion of innovations (4th ed.). New York: The Free Press.

Rogers, E. M., \& Svenning, L. (1969). Modernization among peasants: The impact of communication. New York: Holt, Rinchart and Winston.

Shirley, A. W., Sadanandan, N. K., \& Joseph, A. (1994). Participatory communication: Working for change and development. New Delhi: Sage.

Thompson, B., \& Kinne, S. (1990). Social change theory: Applications to community health. In N. Bracht (Ed.), Health promotion at the community level. Newbury Park, C.A.: Sage Publications.

Uphoff, N. (1985). Putting people first: Sociological variables in rural development. Oxford, UK: Oxford University Press.

Yoon, C. S. (2004). Participatory communication for development. In G. Bessette, \& C. V. Rajasunderam (Eds.), Participatory development communication: A west African agenda. Malaysia: Southbound. 